\title{
Identification and characterization of Diaporthe vaccinii Shear causing upright dieback and viscid rot of cranberry in Poland
}

\author{
Monika Michalecka • Hanna Bryk • Paulina Seliga
}

Accepted: 18 November 2016/Published online: 7 December 2016

(C) The Author(s) 2016. This article is published with open access at Springerlink.com

\begin{abstract}
During the summers of 2013-2014, symptoms similar to viscid rot and upright disease were observed on cranberries (Vaccinium macrocarpon) on one plantation in central Poland. The associated fungi were isolated from symptomatic plant tissue. On the basis of morphological and cultural characteristics and the ability of isolated fungi to elicit viscid rot symptoms on cranberry fruits, they were classified as the genus Diaporthe. Further analysis of ITS sequence data allowed for the classification of the newly obtained isolates as $D$. vaccinii. Additional analysis of genetic diversity using five RAPD and eight ISSR primers constituted additional confirmation of genetic distance existing between closely related $D$. vaccinii and $D$. eres species, enabling their differentiation.
\end{abstract}

Keywords Filamentous fungi · Fruit rot $\cdot$ ITS rDNA analysis $\cdot$ Morphological characteristics $\cdot$ Stem cankers

\section{Introduction}

Plants of Vaccinium macrocarpon (large cranberry or American cranberry) are commercially cultivated in $\mathrm{Eu}-$ rope (Prodorutti et al. 2007) and are becoming more popular also in Poland. However, their cultivation is

\footnotetext{
M. Michalecka $(\bowtie) \cdot$ H. Bryk $\cdot$ P. Seliga

Department of Plant Pathology, Research Institute of Horticulture, Konstytucji 3 Maja 1/3, Skierniewice 96-100, Poland e-mail: monika.michalecka@inhort.pl
}

limited by fungal diseases including those caused by species from the genus Diaporthe Nitschke (anamorph Phomopsis) (Sacc.) Bubák, comprising many important plant pathogenic species with wide host ranges and geographic distributions (Udayanga et al. 2012; Gomes et al. 2013). Several species from the genus Diaporthe were reported as pathogenic to Vaccinium spp. plants in Europe, causing twig blight, stem cankers and fruit rot (Farr et al. 2002b; Tadych et al. 2012; Elfar et al. 2013; Lombard et al. 2014). On the basis of multi-locus DNA sequences analysis, including beta-tubulin, calmodulin, translation elongation factor 1-alpha and the internal transcribed spacer (ITS) regions of the nuclear rDNA, and morphological characteristics, Lombard et al. (2014) classified the collection of European isolates from Vaccinium spp., initially identified as $D$. vaccinii based on host association, to six species, including $D$. vaccinii, $D$. viticola, $D$. eres and three newly described as $D$. asheicola, $D$. baccae and $D$. sterilis. Among these, $D$. vaccinii Shear is globally regarded as the dominant species of Diaporthe on Vaccinium spp. (Farr et al. 2002a; Lombard et al. 2014), causing stem cankers, twig blight, leafspots and soft rot of fruit, mainly on highbush blueberry and cranberry, recognized as 'upright dieback and viscid rot of cranberry' (Farr et al. 2002a, b; Polashock and Kramer 2006; Farr and Rossman 2012; Tadych et al. 2012). D. vaccinii overwinters on the previous year's infected dead twigs and possibly on plant debris (twigs, leaves, fruits) lying on the soil surface (Shear et al. 1931; Wilcox 1939). In the infested areas, the primary inoculum seems to be conidia that are produced in pycnidia of the anamorph Phomopsis vaccinii. Pycnidia are found on dead cankered stems and leaf lesions (Wilcox 
1939; Weingartner and Klos 1975; Parker and Ramsdell 1977). This species, indigenous to North America, is categorised as a quarantine pest for the European Union as indicated in European Food Safety Authority report (EFSA 2014). D. vaccinii is currently present in Latvia (with restricted distribution) and the Netherlands (transient, incidental findings, under surveillance; EFSA 2014). In Germany, the pest has been eradicated (EFSA 2014). In Romania and the United Kingdom, the pest is no longer present, while there are some reports of the pathogen on wild host plants in Lithuania (Kačergius and Jovaišiene 2010).

In addition to the fungi from the genus Diaporthe, showing similar cultural and morphological characteristics between species, other fungal species have been reported to cause stem blight symptoms on Vaccinium spp. similar to those caused by D. vaccinii (e.g. Pestalotiopsis spp., Botryosphaeria dothidea, Godronia cassandrae and Colletotrichum spp.) (MacKenzie et al. 2009; Stromeng and Stensvand 2011; Wright and Harmon 2010; Espinoza et al. 2008). Due to the presence of latent infections (Friend and Boone 1968; Milholland and Daykin 1983), as well as coexistence of some fungal species on one host, diagnosis of the disease based only on symptoms or fungal morphological traits is not reliable. Confirmation of the pathogen identity is required at least by analysing the nuclear ribosomal DNA (rDNA) internal transcribed spacer (ITS) region in axenic cultures of $D$. vaccinii (OEPP/EPPO 2009). A higher level of confidence in the identification can be obtained by a multigene approach to phylogenetic analyses (Udayanga et al. 2012; Elfar et al. 2013; Lombard et al. 2014).

During the survey conducted in the late summers of 2013 and 2014, symptoms similar to those described as viscid rot (soft rot of fruit) and upright dieback on cranberry were observed on one of the few plantations of American cranberry (Vaccinium macrocarpon) located in central Poland. The objective of this study is to identify and characterize the causal agent of the new disease affecting cranberry in Poland based on morphological and genomic features.

\section{Material and methods}

Sampling and isolation of fungi

During the summer of 2013, early leaf discoloration was observed on the 2-year Pilgrim cultivar on one cranberry plantation located in central Poland. The symptoms were scarce, scattered, and similar to those described as 'upright dieback'. In the subsequent year (2014), changes in the appearance of ripening fruits were noted on the same plantation and cultivar. Some of the changes included clearly brighter, reddish-brown, more soft and squashy than healthy-appearing fruits, causing leakage of juice when gently pressed (Fig. 1). Symptomatic cranberry shoots and fruits were collected and disinfected by submerging in $70 \%$ ethanol for $30 \mathrm{~s}$. The small part of the fruit flesh or a fragment of the shoot from the border of diseased and healthy tissue were cut out and placed onto PDA medium in Petri dishes. Plates were incubated at $24{ }^{\circ} \mathrm{C}$ until the production of conidiomata (pycnidia) with spore mass eruptions were observed. Then, a water conidial suspension was prepared and spread evenly onto the PDA surface. After $24 \mathrm{~h}$, single germinating conidial cells were picked up and monoconidial cultures were established on fresh PDA. Finally, seven isolates were obtained including ZA, ZB derived from shoots and A1, A2, P1, D and B obtained from fruits. These isolates were subjected to further morphological and molecular examinations. For comparison purposes, reference strains derived from Centraalbureau voor Schimmelcultures in the Netherlands: CBS 160.32 (type culture of $D$. vaccinii Shear, derived from $V$. macrocarpon) and CBS 524.82, derived from $V$. vitis-idaea and reported by Lombard et al. (2014) as D. eres, and one strain Lat4 (Diaporthe sp., from cranberry shoots cv. Pilgrim, Latvia; 2014) from the collection of Research Institute of Horticulture (RIH), Skierniewice, were included to analyses.

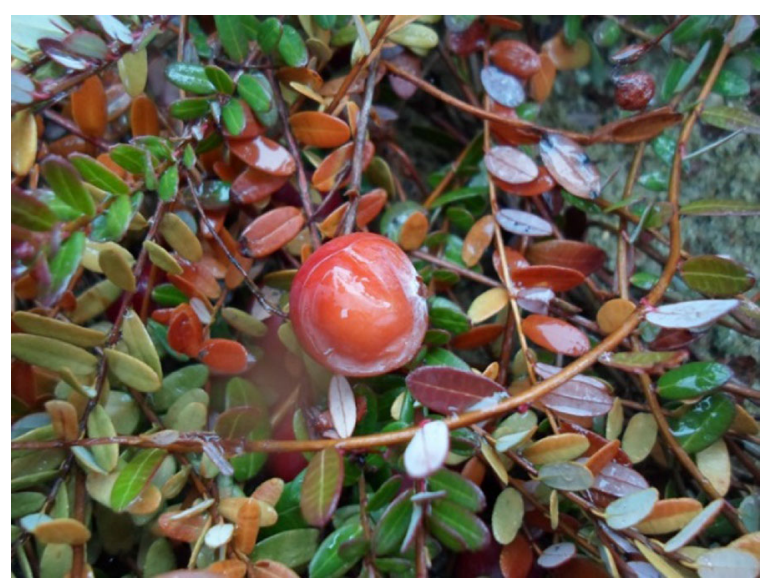

Fig. 1 Symptoms of viscid rot caused by D. vaccinii on cranberry fruit 
Morphology and growth examination

For the examination of morphology of all 10 isolates and strains cultured in vitro, four types of microbiological media were tested. Three of the media: PDA (Potato Dextrose Agar; Becton Dickinson, Sparks, MD, USA), MEA (Malt Extract Agar; Difco Detroit, USA) and CMA (Corn Meal Agar; Difco, Detroit, USA) were prepared according to the manufacturer's instruction. The fourth medium was MSM prepared from dried stems of sweet clover according to the procedure in Appendix 2 of the EPPO standard diagnostic protocol (OEPP/EPPO 2009). Agar plugs (6 $\mathrm{mm}$ in diameter) from the edge of 10-day-old cultures grown on PDA medium were transferred onto newly prepared media, and cultures were incubated at $24{ }^{\circ} \mathrm{C}$ in 8 -h light/16-h darkness photoperiod. Colony morphology and growth were observed and measured for eight consecutive days. Mean growth rates per $24 \mathrm{~h}$ were compared between isolates using one-way ANOVA followed by Tukey's post-hoc honestly significance difference test (STATISTICA). Each experiment was performed twice with five replicates for each isolate.

For each isolate and strain, the morphology and dimensions of conidia obtained in in vitro cultures were determined under an optical light microscope (Eclipse $80 i$, Nikon, Chiyodaku, Tokyo, Japan) combined with digital camera. For each isolate, 100 alpha and - if present -50 beta conidia were observed and measured at $600 \mathrm{x}$ magnification. For isolates and strains where no conidia production was observed on any used medium, mycelia were transplanted onto PDA in Petri dishes supplemented with carnation leaf fragments that were previously disinfected with $96 \%$ ethanol and washed with sterile water. After mycelial plug transfer, the plates were incubated in the same conditions as plates containing only media.

DNA extraction, PCR and sequencing

Approximately $100 \mathrm{mg}$ of a mycelium was cut out from 10-day-old cultures grown on PDA medium and ground using a glass rod in an Eppendorf tube. The total DNA was extracted using the GeneMatrix Plant \& Fungi DNA Purification Kit (EURx, Gdańsk, Poland) according to the manufacturer's instructions.

The ITS region of nuclear rDNA of each examined isolate was amplified using the universal fungal primers ITS1 and ITS4 (White et al. 1990) using the PCR conditions described by Chen et al. (2006). Reaction mixtures consisted of $2.5 \mu \mathrm{l}$ of extracted DNA, $1 \mu \mathrm{M}$ of each primer, $0.2 \mathrm{mM}$ of each dNTP, $1.5 \mathrm{U}$ of DreamTaq Green DNA Polymerase (Thermo Scientific, Vilnius, Lithuania), 1x optimised DreamTaq Green Buffer and double distilled water up to $50 \mu \mathrm{l}$. PCR products were purified using the QIAquick ${ }^{\circledR}$ Gel Extraction Kit (Qiagen, Hilden, Germany) and sequenced in both directions using the same primer pair. Obtained sequences were compared with the 20 sequences of Diaporthe spp. and Phomopsis spp. strains, originating from or reported previously on Vaccinium plants (Elfar et al. 2013; Lombard et al. 2014) and with three sequences from other hosts, all available in GenBank database (National Center for Biotechnology Information). Comparisons were performed by cluster analysis conducted with MEGA v. 6.0 software (Tamura et al. 2013; available at www.megasoftware.net/mega.php). Phylogenetic relationships between sequences were inferred using the neighbor-joining and maximum likelihood method and the heuristic search. Bootstrap support values based on 1,000 replications were calculated for tree branches in both phylogenetic methods. From all ITS1-5.8S-ITS2 rDNA sequences obtained in this study, three representatives were selected (from isolates A1, D and Lat4) and deposited in GenBank and were assigned with the accession numbers. The sequences of eight examined isolates were aligned with the corresponding sequences of reference strains CBS 160.32 and CBS 524.82, and additionally with the sequences of CBS 138594 strain (ex-epitype of $D$. eres, derived from Ulmus laevis, Germany), CBS 134742 (D. eres from V. oxycoccus, Lithuania) and CPC 23806 (D. eres from Vaccinium sp., Germany) all from the GenBank, and the percentage of similarity between them was calculated using MEGALIGN software (DNASTAR Inc.).

Pathogenicity test on cranberry fruits

Conidia of eight Diaporthe spp. isolates were suspended in sterile double-distilled water, counted using a haemocytometer and adjusted to a final concentration of $1 \times 10^{5}-10^{6} \mathrm{CFU}$ (colony-forming units) $/ \mathrm{ml}$. Cranberry fruits were inoculated by introducing $100 \mu \mathrm{l}$ of conidial suspension into a natural opening formed after the removal of the stalk. In cases when the production of conidia was not observed (CBS 524.82, CBS 160.32), fruits were inoculated with 3-mm diameter mycelial plugs of that isolate. Fruits with plugs from sterile 
PDA agar or injected with water droplets were used as a negative control. Inoculated fruits were incubated for 14 days at room temperature in a sterilized glass container filled with water-soaked cotton wool, maintaining 90-95\% relative humidity. The experiment was repeated twice with 10 fruits per each isolate. After completion of the experiment, the suspected causal agent was reisolated from symptomatic fruits onto PDA and its identity was confirmed in order to fulfil Koch's postulates.

Genetic diversity evaluation based on RAPD and ISSR markers

DNA extracted from all eight examined isolates and two reference strains was tested in two types of fingerprinting PCR assays. Amplification patterns were generated in separate reactions with eight ISSR primers as follows: $(\mathrm{GACA})_{4}$ (Weising et al. 1989); $(\mathrm{GACG})_{4},(\mathrm{GCA})_{5}$ (Talhinhas et al. 2005); (ACTG) (Urena-Padilla et al.

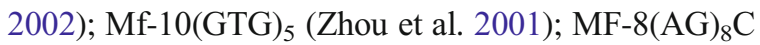
(Ma et al. 2003); (GTC) 6 , (AC) 8 T (Fan et al. 2010) and five RAPD primers: OPT-07, OPC-05, OPU-19, OPAR03 and OPA-11 (Operon Technologies Inc., CA, USA). Conditions of amplification for ISSR-PCR assays were as follows: 3 min of denaturation at $94{ }^{\circ} \mathrm{C}, 30$ cycles of $30 \mathrm{~s}$ at $94{ }^{\circ} \mathrm{C}, 30 \mathrm{~s}$ at an appropriate annealing temperature: $48{ }^{\circ} \mathrm{C}$ for $(\mathrm{GACA})_{4},(\mathrm{ACTG})_{4}$, and $(\mathrm{AG})_{8} \mathrm{C}$, $50{ }^{\circ} \mathrm{C}$ for $(\mathrm{AC})_{8} \mathrm{~T}, 52{ }^{\circ} \mathrm{C}$ for $(\mathrm{GACG})_{4}, 55{ }^{\circ} \mathrm{C}$ for $(\mathrm{GCA})_{5}$ or $60{ }^{\circ} \mathrm{C}$ for $(\mathrm{GTG})_{5}$ and $(\mathrm{GTC})_{6}, 90 \mathrm{~s}$ at $72{ }^{\circ} \mathrm{C}$, ending with one cycle of $5 \mathrm{~min}$ at $72{ }^{\circ} \mathrm{C}$. For amplifications with RADP primers, 40 cycles in similar conditions were performed, with the exceptions of an annealing step for $45 \mathrm{~s}$ at $36^{\circ} \mathrm{C}$ and polymerization for $1 \mathrm{~min}$ at $62{ }^{\circ} \mathrm{C}$ for OPT-07, OPC-05, OPU-19 primers, and an annealing step for $90 \mathrm{~s}$ at $38^{\circ} \mathrm{C}$ and polymerization for 2 min at $72{ }^{\circ} \mathrm{C}$ for the OPAR-03 and OPA-11 (Operon Technologies) primers. Each reaction contained $1 \mu \mathrm{M}$ of ISSR or $0.8 \mu \mathrm{M}$ of RAPD primer, $0.2 \mathrm{mM}$ of each dNTP, $0.55 \mathrm{U}$ of DreamTaq Green DNA Polymerase, 1x optimised DreamTaq Green Buffer and double-distilled water up to $20 \mu \mathrm{l}$. All RAPD and ISSR-PCR assays were performed twice.

Products obtained in all PCR-based experiments were separated on $1.5 \%(\mathrm{w} / \mathrm{v})$ agarose gels and stained with ethidium bromide, visualised on a UV transilluminator and documented. Product sizes were estimated based on O'GeneRuler ${ }^{\mathrm{TM}}$ 100-bp DNA Ladder Plus (Thermo Scientific, Vilnius, Lithuania).

\section{Results}

Morphology and growth examination

For all ten fungal isolates and strains cultured on four different media, a consistent radiate growth pattern was observed. The highest mean growth rates for A1, A2, D, $\mathrm{B}, \mathrm{P} 1, \mathrm{ZA}, \mathrm{ZB}$, and CBS 160.32 isolates and strains were observed on MEA medium (9.52-11.85 mm/day), while the lowest rates of all strains were observed on MSM medium (5.82-7.62 mm/day) (Table 1). For the Lat4 and CBS 524.82 strains, the highest growth rates were observed on PDA and on MEA, respectively. Colony morphology was similar for each isolate cultured on PDA and MEA, comprising zonation and pigmentation of aerial mycelia, visible also on the reverse side (Fig. 2a and $b$ ). Colonies on PDA and MEA observed after 8 days of growth were white, with a brownish-grey colouration around the agar plug and clear zonation, surface mycelium cottony, margin feathery. On MSM medium, mycelia were downy with zonation, but without the pigmentation and stromata (Fig. 2d), while mycelia cultured on CMA medium were very soft, almost transparent, with zonation but without pigmentation, and growth was almost entirely inside the agar (Fig. 2c). The growth rates for Lat4 and CBS 524.82 strains were always the highest on all media (Table 1). The fastest conidiomata formation, scattered in concentric circles on the mycelium surface, was observed for A1, A2, P1, B, D, ZA and ZB isolates during their growth on PDA and MEA medium, clearly visible from 14 day of incubation (d.o.i.). On MSM and CMA media, conidiomata formation was observed after 27 d.o.i. only for single strains. Within these structures, the conidia production was recorded on PDA and MEA (Fig. 2g), beginning from 16 d.o.i. for isolates A1, A2, $\mathrm{P} 1, \mathrm{~B}, \mathrm{D}, \mathrm{ZA}$ and ZB. Alpha conidia were observed in the following size ranges: length of $6.5-8.5 \mu \mathrm{m}$, width of 2.9-4.3 $\mu \mathrm{m}$ (Table 2), hyaline, unicellular, fusiform, straight, mostly biguttulate, aseptate (Fig. 2f). Besides alpha conidia, the presence of filiform, unicellular, uncinated and eguttulate beta conidia, less abundant, were observed only for the D isolate (length of $16.2 \mu \mathrm{m} \pm 0.47 \mathrm{SEM}$; width of $1.9 \mu \mathrm{m} \pm 0.08 \mathrm{SEM}$; Fig. 2e). Strains CBS 524.82, CBS 160.32 and Lat 4 did not produce conidia on any medium; however, strain Lat4 was able to produce pycnidia and release spore masses in the presence of carnation leaves on PDA only when mycelium was growing directly on plant tissue. Here, alpha and beta conidia were observed from the 
Table 1 Mean growth rate of mycelium D. vaccinii and D. eres strains, growing on four different media: PDA, MEA, CMA and MSM

\begin{tabular}{|c|c|c|c|c|c|c|c|c|}
\hline \multirow[b]{2}{*}{ strain } & \multicolumn{7}{|c|}{ Mean mycelium growth rate per $24 \mathrm{~h}$ in $\mathrm{mm}, \pm$ SEM } & \multirow[b]{2}{*}{$\begin{array}{l}\text { Tukey HSD } \\
\text { test for means }\end{array}$} \\
\hline & PDA & $\begin{array}{l}\text { Tukey HSD } \\
\text { test for means }\end{array}$ & MEA & $\begin{array}{l}\text { Tukey HSD } \\
\text { test for means }\end{array}$ & CMA & $\begin{array}{l}\text { Tukey HSD } \\
\text { test for means }\end{array}$ & MSM & \\
\hline A1 & $9,38 \pm 0,38$ & \multirow[t]{7}{*}{$9.27 \pm 0.17 \mathrm{e}^{*}$} & $10,33 \pm 0,37$ & \multirow[t]{7}{*}{$10.71 \pm 0.12 \mathrm{fgh}$} & $8,38 \pm 0,31$ & \multirow[t]{7}{*}{$8.52 \pm 0.14 \mathrm{~d}$} & $7,62 \pm 0,32$ & \multirow{10}{*}{$6.90 \pm 0.11 \mathrm{ab}$} \\
\hline A2 & $9,58 \pm 0,35$ & & $10,15 \pm 0,35$ & & $8,68 \pm 0,40$ & & $6,82 \pm 0,27$ & \\
\hline P1 & $9,20 \pm 0,33$ & & $10,15 \pm 0,29$ & & $8,60 \pm 0,38$ & & $6,65 \pm 0,34$ & \\
\hline B & $9,23 \pm 0,45$ & & $11,13 \pm 0,25$ & & $8,50 \pm 0,40$ & & $6,92 \pm 0,34$ & \\
\hline $\mathrm{D}$ & $8,77 \pm 0,50$ & & $11,85 \pm 0,37$ & & $7,87 \pm 0,25$ & & $6,20 \pm 0,25$ & \\
\hline $\mathrm{ZA}$ & $9,56 \pm 0,51$ & & $10,75 \pm 0,21$ & & $8,87 \pm 0,36$ & & $6,98 \pm 0,26$ & \\
\hline $\mathrm{ZB}$ & $9,13 \pm 0,63$ & & $10,62 \pm 0,26$ & & $8,77 \pm 0,52$ & & $7,10 \pm 0,29$ & \\
\hline $\begin{array}{l}\text { CBS } 160.32 \\
\quad(\text { D. vaccinii })\end{array}$ & \multicolumn{2}{|c|}{$8,23 \pm 0.35$ cde } & \multicolumn{2}{|c|}{$9.52 \pm 0.31$ defg } & \multicolumn{2}{|c|}{$8.07 \pm 0.28$ bcde } & $5.82 \pm 0.22 \mathrm{a}$ & \\
\hline Lat4 & \multicolumn{2}{|c|}{$15.52 \pm 0.42 \mathrm{k}$} & \multicolumn{2}{|l|}{$13.7 \pm 0.26 \mathrm{j}$} & \multicolumn{2}{|c|}{$11.93 \pm 0.43 \mathrm{hi}$} & $11.23 \pm 0.30 \mathrm{ghi}$ & \\
\hline $\begin{array}{c}\text { CBS } 524.82 \\
\text { (D. eres) }\end{array}$ & \multicolumn{2}{|c|}{$9.47 \pm 0.26 \mathrm{def}$} & \multicolumn{2}{|c|}{$12.03 \pm 0.26 \mathrm{ij}$} & \multicolumn{2}{|c|}{$9.60 \pm 0.33 \mathrm{defg}$} & $7.02 \pm 0.28 \mathrm{abc}$ & \\
\hline
\end{tabular}

SEM - standard error of the mean

$\mathrm{n} / \mathrm{o}$ - not observed in this study

* the same letters indicate lack of statistically significant differences between values in columns, according to the Tukey HSD test

16th d.o.i., alpha were aseptate, hyaline, fusiform, straight, bi- or multiguttulate (length of $7.3 \mu \mathrm{m} \pm 0.08$ SEM; width of $2.8 \mu \mathrm{m} \pm 0.04$ SEM, Table 2), while beta were aseptate, hyaline, fusiform to hooked, eguttulate, smooth and uncinated (in size $22.5 \times 1.7 \mu \mathrm{m}$ ). On the basis of examined morphological features of fungi cultured on agar media, the isolates A1, A2, P1, B, D, ZA and $\mathrm{ZB}$ were preliminary classified as the genus Diaporthe, and the genus affiliation of Lat4 strain was confirmed.

\section{ITS rDNA analysis}

The newly obtained nucleotide sequences of isolates A1, A2, P1, B, D, ZA and ZB, comprising the ITS15.8S rDNA-ITS2 region showed high similarity (99.6\%) with the corresponding DNA region of reference strain CBS 160.32 of D. vaccinii, while the sequence of Lat4 strain showed $100 \%$ similarity with the sequence of D. eres CBS 134742 from Lithuania, 99.4\% with sequence of $D$. eres CPC 23806 from Germany and 97.4\% with sequences of $D$. eres CBS 524.82 from Poland and of ex-epitype D. eres CBS 138594 from Germany. The resulting dendrogram, comprising sequences of the analysed isolates and strains together with 23 sequences of other strains, reported on Vaccinium or other hosts, clustered the seven analysed isolates together with reference strains of $D$. vaccinii CBS 160.32 (Fig. 3), enabling classification of these isolates as $D$. vaccinii species. The strain Lat4 was clustered together with two strains of $D$. eres, which was supported by high bootstrap values (Fig. 3). However, other D. eres strains: CBS 524.82 from Poland, CBS 138594 from Germany and CPC 23809 from Lithuania segregated into another separate group, although in one clade. Based on this segregation, Lat4 was classified as $D$. eres species. Maximum likelihood analysis resulted in a dendrogram with the same topology and very similar bootstrap values as those obtained by neighbor-joining analysis. Therefore, the NJ-tree was chosen based on these two graphic presentations and is presented here.

\section{Pathogenicity test}

Leaking juice was observed on the cranberry fruits from the 8th day of inoculation, but typical swollenappearing symptoms occurred on 13-16 day after inoculation (Fig. $2 \mathrm{~h}$ and $\mathrm{i}$ ). All ten examined Diaporthe strains were associated with the above described symptoms. Symptomatic fruits inoculated with $D$. vaccinii strains released viscid juice when touched. The identity of re-isolated fungi with those used for inoculation was confirmed. 


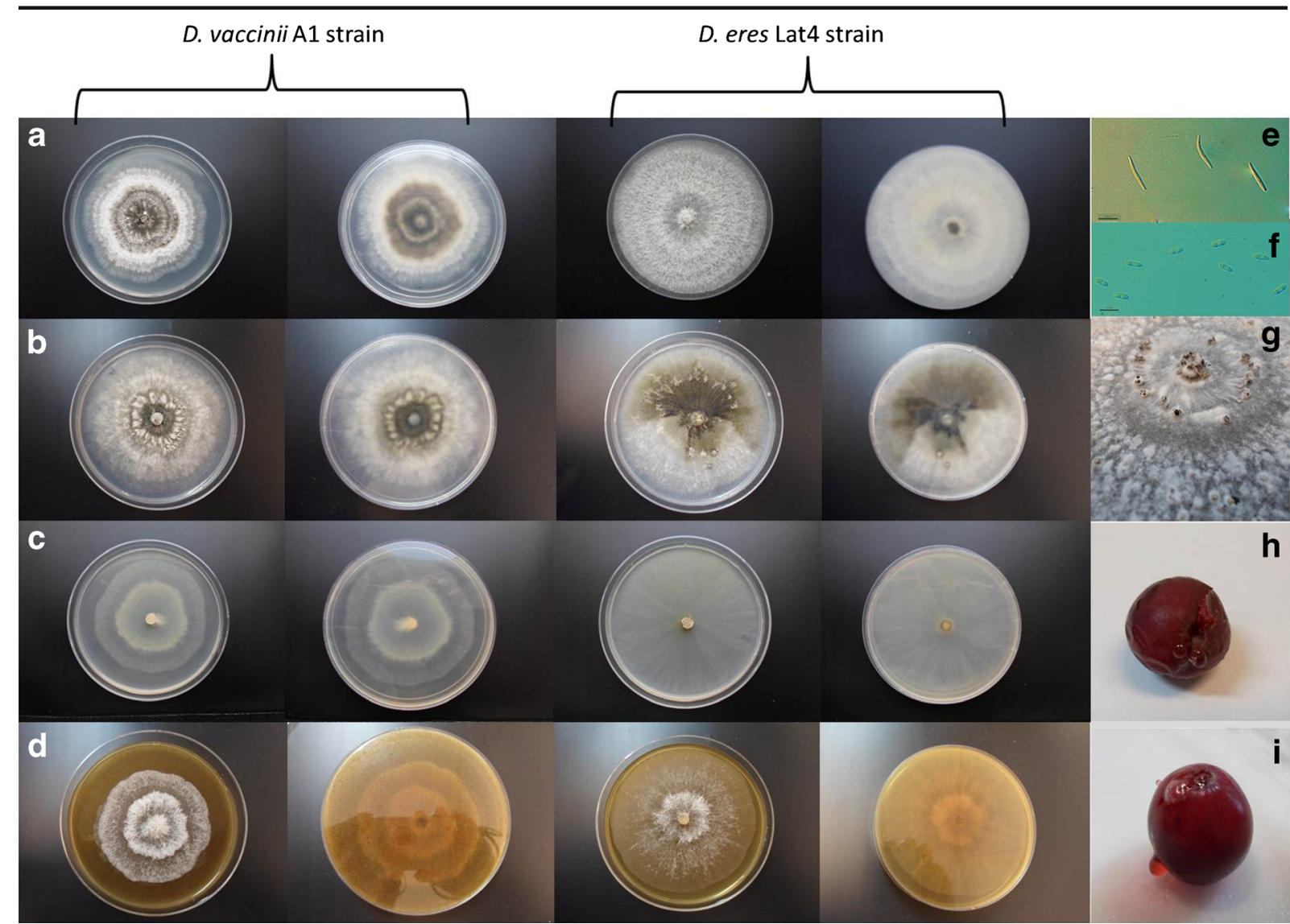

Fig. 2 Morphology of 8-day-old mycelia of D. vaccinii (A1) and D. eres (Lat4) strains growing on (a) PDA, (b) MEA, (c) CMA and (d) MSM media. (e) Beta and (f) alpha conidia of D. vaccinii

\section{ISSR and RAPD PCR assays}

A total of 105 reproducible bands were obtained in the ISSR-PCR assay, ranging in size from $300-4,000 \mathrm{bp}$, and 63 bands of 200-4,000 bp were obtained in the RAPD PCR assay. In both assays, a low variability was observed between eight $D$. vaccinii strains, while the amplification patterns obtained for $D$. eres strains (Lat4 and CBS 524.82) were clearly different from those obtained for D. vaccinii strains but similar to each other (Fig. 4).

\section{Discussion}

Although various fungal species can be associated with similar stem blight symptoms or fruit rot on Vaccinium spp. plants (Olatinwo et al. 2003; Espinoza et al. 2008; MacKenzie et al. 2009; Stromeng and Stensvand 2011; Wright and Harmon 2010; Lombard et al. 2014), in our strain D. (g) Conidiomata sporulating on PDA. (h and i) Symptoms of viscid rot on cranberry fruit after artificial infection with D. vaccinii spores, 8 days post inoculation study the causal agent on cranberry growing in one location in central Poland was classified as D. vaccinii Shear. Due to intensive plant material exchange and possible latent fungal infections, as well as close proximity of other, non-cultivated host plants, we should be aware of the possibility of introducing new and particularly harmful pathogenic fungal species to cultivated Vaccinium plants in our country. Cranberry fruits are infected at all stages of their development, but infections remain latent until fruit maturity. Infected berries become reddish-brown, soft, mushy, often splitting with leakage of juice (viscid rot) at harvest (Milholland and Daykin 1983). Similarly, in our study the first typical symptoms of viscid rot were observed on naturally affected mature fruits, sampled at harvest time, and they were also found in artificial infections.

Fungi from the genus Phomopsis are characterized by ostiolate, black conidiomata containing elongate, cylindrical phialides that may produce two types of hyaline, non- 
Table 2 Mean conidia size of $D$. vaccinii and D. eres strains growing on PDA or PDA with carnation leaves (details in the text)

\begin{tabular}{|c|c|c|c|c|}
\hline \multirow{3}{*}{ strain } & \multicolumn{4}{|c|}{ Mean conidia size in $\mu \mathrm{m}, \pm \mathrm{SEM}$} \\
\hline & \multicolumn{2}{|l|}{ Alpha } & \multicolumn{2}{|l|}{ Beta } \\
\hline & length & width & length & width \\
\hline A1 & $7,59 \pm 0,12$ & $4,28 \pm 0,11$ & $\mathrm{n} / \mathrm{o}$ & $\mathrm{n} / \mathrm{o}$ \\
\hline $\mathrm{A} 2$ & $7,60 \pm 0,11$ & $3,73 \pm 0,09$ & $\mathrm{n} / \mathrm{o}$ & $\mathrm{n} / \mathrm{o}$ \\
\hline $\mathrm{P} 1$ & $7,64 \pm 0,13$ & $3,77 \pm 0,11$ & $\mathrm{n} / \mathrm{o}$ & $\mathrm{n} / \mathrm{o}$ \\
\hline B & $7,89 \pm 0,17$ & $2,97 \pm 0,08$ & $\mathrm{n} / \mathrm{o}$ & $\mathrm{n} / \mathrm{o}$ \\
\hline $\mathrm{D}$ & $6,49 \pm 0,12$ & $2,93 \pm 0,09$ & $16,22 \pm 0,47$ & $1,91 \pm 0,08$ \\
\hline $\mathrm{ZA}$ & $8,32 \pm 0,11$ & $3,11 \pm 0,11$ & $\mathrm{n} / \mathrm{o}$ & $\mathrm{n} / \mathrm{o}$ \\
\hline ZB & $8,53 \pm 0,10$ & $3,17 \pm 0,10$ & $\mathrm{n} / \mathrm{o}$ & $\mathrm{n} / \mathrm{o}$ \\
\hline CBS 160.32 (D. vaccinii) & $\mathrm{n} / \mathrm{o}$ & $\mathrm{n} / \mathrm{o}$ & $\mathrm{n} / \mathrm{o}$ & $\mathrm{n} / \mathrm{o}$ \\
\hline Lat4 & $7,33 \pm 0,08$ & $2,79 \pm 0,04$ & $22,46 \pm 0,57$ & $1,73 \pm 0,05$ \\
\hline CBS 524.82 (D. eres) & $\mathrm{n} / \mathrm{o}$ & $\mathrm{n} / \mathrm{o}$ & $\mathrm{n} / \mathrm{o}$ & $\mathrm{n} / \mathrm{o}$ \\
\hline
\end{tabular}

SEM - standard error of the mean

$\mathrm{n} / \mathrm{o}$ - not observed in this study

septate conidia, named alpha and beta (Rehner and Uecker 1994). Beta conidia are not always produced, thus are not used for identification, but when present, they usually are unicellular, filiform and uncinate, 16.0-24.0 $\mu \mathrm{m}$ long and 1.0-1.5 $\mu \mathrm{m}$ wide (OEPP/EPPO 2009). Beta conidia, observed among our D. vaccinii strains only for D strain, showed similar dimensions as those previously reported, but the mean width was slightly out of the range. Both morphology in culture and dimensions of alpha conidia of examined D. vaccinii strains were similar to those observed by Farr et al. (2002a) who reported alpha conidia in ranges of 5.9-11.3 $\mu \mathrm{m}$ long $\times 2.1-3.9 \mu \mathrm{m}$ wide and by OEPP/EPPO (2009) reporting alpha sizes of 6-11 $\times 2.5$ $4 \mu \mathrm{m}$, except from alpha conidia of strain A1, whose mean width was $4.28 \mu \mathrm{m}$. As reported by Udayanga et al. (2014), colonies of $D$. eres strains growing on PDA in the dark at $25^{\circ} \mathrm{C}$ for 1 week showed growth rates of $5.5 \pm$ $0.2 \mathrm{~mm} /$ day, and white, aerial, fluffy mycelium with dark pigmentation developing in the centre, producing abundant black stromata at maturity. Dimensions of conidia of the Lat 4 . eres strain were similar to those reported by Udayanga et al. (2014): alpha 6-9 $\mu \mathrm{m}$ long x 3-4 $\mu \mathrm{m}$ wide and beta: $18-29 \mu \mathrm{m}$ long $\times 1-1.5 \mu \mathrm{m}$ wide, with the exception of beta conidia width-slightly out of this range, while the mean growth rate on PDA was three times higher than reported, although Lat4 mycelium grown in light/dark regime, without producing any pycnidia. According to OEPP/EPPO (2009), P. vaccinii grows well on PDA,
MEA and MSM up to $10-12 \mathrm{~mm}$ in diameter/day, where MSM medium is considered preferable for pycnidia and conidia production. In our study, newly obtained isolates of D. vaccinii showed fast growth on four examined media, with mean growth rates ranging from $6.9 \pm 0.11$ (MSM) to $10.7 \pm 0.12$ (MEA) $\mathrm{mm} /$ day, but no reproductive structures were observed on MSM medium. The $8 \mathrm{~h} / 16 \mathrm{~h}$ light/dark regime was suitable to induce sporulation from the 16th day of growth on PDA and MEA. On the basis of colony colour growing on PDA, Kanematsu et al. (1999) designated two groups: W-type, producing white aerial hyphae with scattered stroma and irregular pycnidial locules, producing both alpha and beta conidia, and G-type, with few aerial hyphae, white to grey and forming abundant small pycnidial stroma with irregular pycnidial locules, producing only alpha conidia from the 16th day of incubation. Based on the whitish appearance with zonation, the D. vaccinii strains analysed in the study could be classified as the W-type colonies, although most of them only produced alpha conidia. The colony morphology of Lat 4 and CBS 524.82 strains was clearly distinct from that of D. vaccinii strains, producing brownish inclusions within flat mycelia; however, because neither conidiomata nor conidia were produced during their growth on PDA, it is hard to reliably classify them based on colony type.

Since some of the morphological features depend on the cultural conditions and media used, including the zonation and pigmentation of aerial mycelia which may 


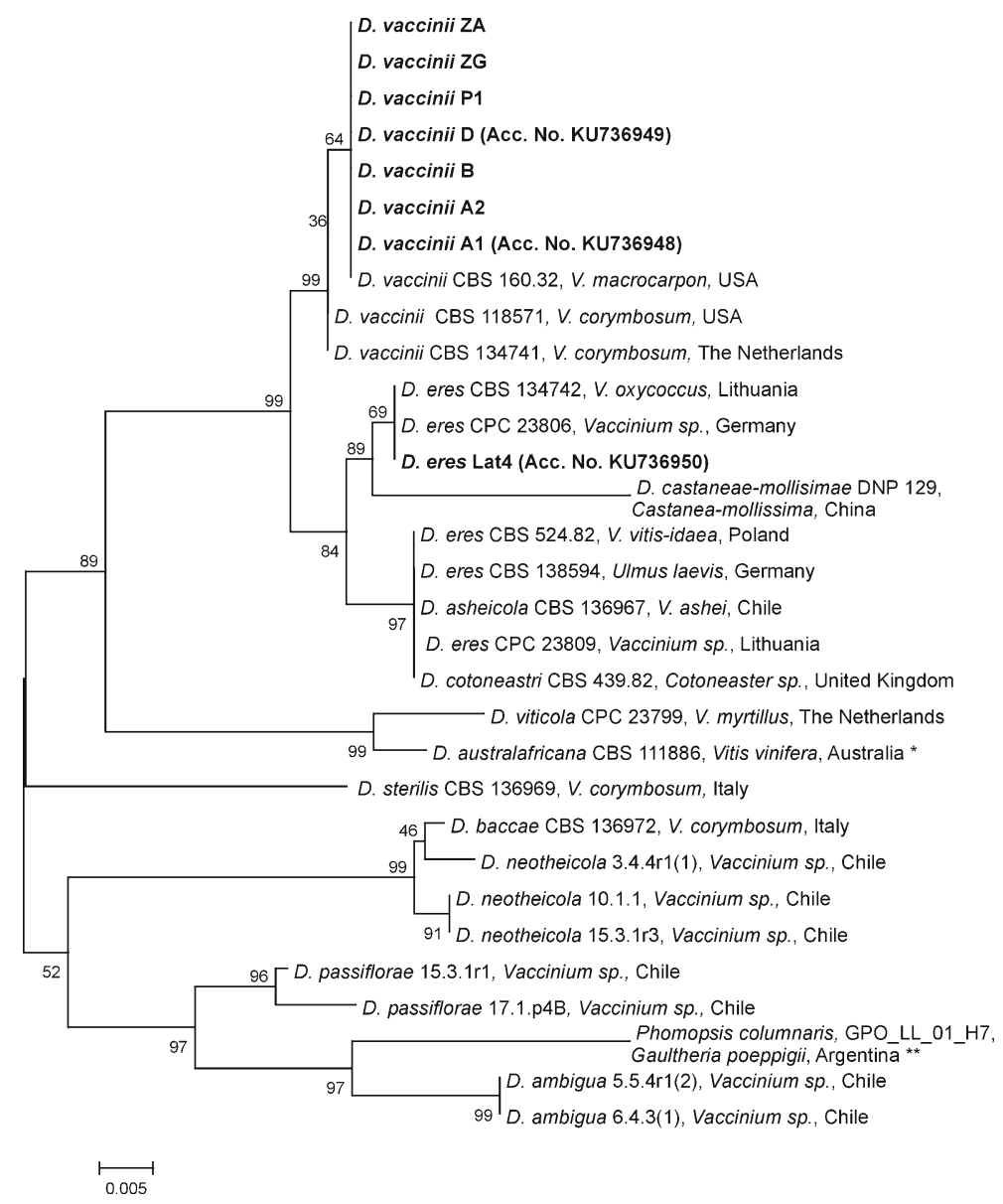

Fig. 3 The evolutionary history of 30 Diaporthe and 1 Phomopsis strains was inferred using the neighbor-joining method. The optimal tree with the sum of branch length $=0.271$ is shown. The percentage of replicate trees in which the associated taxa clustered together in the bootstrap test (1,000 replicates) are shown next to the branches. The evolutionary distances were computed using the Kimura 2-parameter method and are in the units of the number of base substitutions per site (scale). The analysis involved 31 nucleotide sequences. All positions containing gaps and missing data were eliminated. There were a total of 467 positions analysed in the final dataset. Among the sequences of strains originating from non-Vaccinium hosts, those with asterisks were reported on Vaccinium spp. elsewhere (* - Elfar et al. 2013, ** - Farr et al. 2002b)

and structures of mycelia produced by different Diaporthe species were reported (Rehner and Uecker

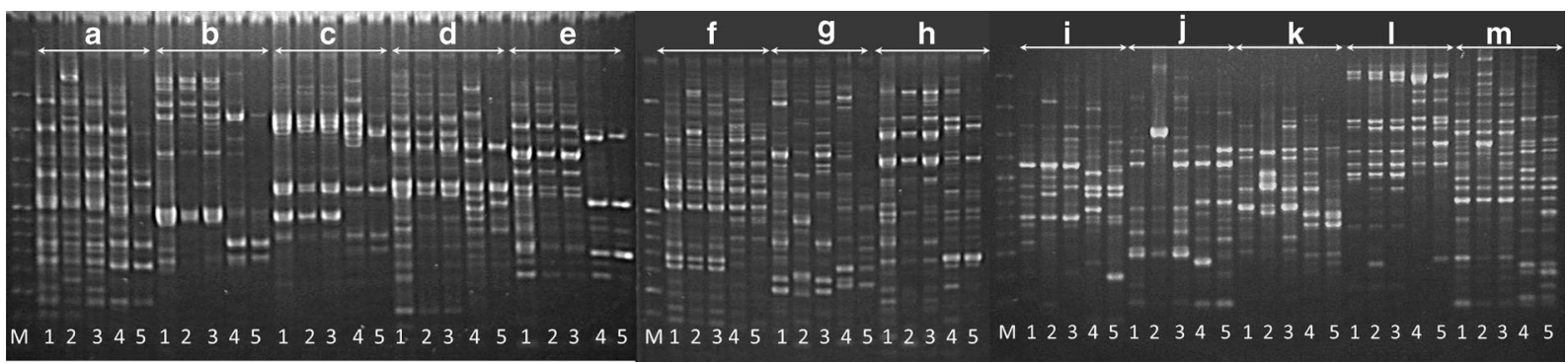

Fig. 4 Amplification patterns obtained by PCR with: (a) $(\mathrm{GCA})_{5}$, (b) $(\mathrm{AC})_{8} \mathrm{~T},(\mathbf{c})(\mathrm{ACTG})_{4},(\mathbf{d}) \mathrm{MF}-8(\mathrm{AG})_{8} \mathrm{C},(\mathbf{e})(\mathrm{GACA})_{4},(\mathbf{f})$ $(\mathrm{GACG})_{4},(\mathbf{g}) \mathrm{Mf}-10(\mathrm{GTG})_{5}$ and (h) $(\mathrm{GTC})_{6}$ ISSR primers and (i) OPU-19, (j) OPT-07, (k) OPC-05, (l) OPA-11 and (m) OPAR-
03 RAPD primers for representative strains of Diaporthe spp. used in the study. Lanes $1-5$ contain DNA of: 1 - strain CBS 160.32, 2 - strain A1, 3 - strain D, 4- strain CBS 524.82, 5 - strain Lat4. M O'GeneRuler ${ }^{\mathrm{TM}} 100$ bp Plus DNA Ladder 
1994; Santos and Philips 2009; Gomes et al. 2013; Udayanga et al. 2014), this makes it no longer possible to precisely distinguish the species of Diaporthe based on morphological features alone. The results of comparative study conducted here also indicate that both analysed Diaporthe species have similar culture morphologies and overlapping conidial dimensions, making differentiation ineffective.

A preliminary approach toward species recognition and characterization is usually based not only on morphology and culture characteristics, but also on host affiliation (Rehner and Uecker 1994; Santos and Philips 2009). However, recent studies of the Diaporthe genus show that since the same species can be found on different hosts and several species can occur on the same host, host association cannot be the determinant for species definition (Gomes et al. 2013). Our finding of strains belonging to two different Diaporthe species and derived from Vaccinium macrocarpon plants is congruent with this statement. Recent recommendations are to validate conventional diagnostic methods with molecular techniques. Those based on single- or multi-locus genetic information, applying among others ITS rDNA, partial sequence of EF $1-\alpha$ or actin, DNA-lyase, mating type, beta-tubulin or calmodulin genes (Udayanga et al. 2014) are particularly helpful in redefining species in this genus, especially when cryptic species need to be resolved. The ITS region of ribosomal gene clusters, although commonly used to infer phylogenies in fungi (Nilsson et al. 2008), was recently demonstrated to show high within-species variation in some Diaporthe/Phomopsis species (Santos et al. 2010). However, in the study performed by Diogo et al. (2010) it was still possible to distinguish species in this genus using ITS data, due to little species variation of $P$. amygdali. The phylogenetic analysis performed by Udayanga and others (2014) showed that, beside several other analysed DNA regions, clear (99-100\% bootstrap value) distinction of D. vaccinii strain CBS 160.32 from the closely related $D$. alleghaniensis strain, based on rDNA ITS sequence only. A similar trend was observed in our phylogenetic analysis: seven examined strains formed a uniform clade with the CBS 160.32 strain and the same phylogenetic group with other $D$. vaccinii strains, and were clearly distinct from other clades and groups of species containing $D$. eres strains. Thus, in our study, it was possible to classify those strains as $D$. vaccinii species.
The species grouping based on ITS sequences obtained by Diogo et al. (2010) and Santos and Phillips (2009) was consistent with the groups revealed using the ISSRPCR assay. In our study, the ISSR-PCR and RAPD assays provided additional confirmation of genetic distance existing between $D$. vaccinii and another closely related Diaporthe species (occurring on cranberry) and justifies their affiliation to distinct species. The reciprocal similarity of all $D$. vaccinii strains, including the reference CBS 160.32 strain, was clear in both analyses. Although the Lat4 strain showed similar amplification patterns as those of CBS 524.82 strain belonging to D. eres (Lombard et al. 2014), was not directly grouped according to ITS sequence with this strain, but was clustered with $D$. eres strains from Lithuania and Germany. These results may derive from the sequence variability within the ITS1-5.8S-ITS2 rDNA region within the $D$. eres species, what is consistent with the finding of Udayanga et al. (2014), where sequence heterogeneity of ITS within the species was observed. Although morphological and genetic characteristics of the Lat4 strain indicated its affiliation to the Diaporthe genus, and, the most probably, to $D$. eres species, a multi-locus data analysis involving at least EF1- $\alpha$, Apn2 and HIS genes, as proposed by Udayanga et al. 2014, is required for better resolving the genetic distinction between Lat4 and some $D$. eres strains.

\section{Conclusions}

Preliminary species-recognition criteria of the Diaporthe genus has been based on morphological features, colony characteristics and host affiliation. However, the current status of the taxonomic position of Diaporthe spp. primarily focuses on molecular data obtained from phylogenetic species recognition (Udayanga et al. 2012, 2014). On the basis of studies by conventional and molecular biology methods, seven fungal isolates obtained from cranberry plants showing viscid rot and upright dieback symptoms, were identified as Diaporthe vaccinii Shear. This is the first study and confirmed identification of this species in Poland, which is a quarantine organism from A2 list (EPPO 2014). This pathogen was detected with restricted distribution on one cranberry plantation in the center of the country, and the entire affected plant material was destroyed. This is also the second after Lombard et al. (2014) report of the occurrence of D. eres on Vaccinium plant. 
Acknowledgements The authors highly appreciate the help and useful suggestions from Dr. Grażyna Szkuta and are also grateful for the possibility of performing some parts of this study in the Central Laboratory of Main Inspectorate of Plant Health and Seed Inspection in Torun, Poland. The authors would like to thank Paweł Trzciński MSc from the Laboratory of Rhizosphere, Research Institute of Horticulture, for precious help in documentation of microscopic observations.

Open Access This article is distributed under the terms of the Creative Commons Attribution 4.0 International License (http:// creativecommons.org/licenses/by/4.0/), which permits unrestricted use, distribution, and reproduction in any medium, provided you give appropriate credit to the original author(s) and the source, provide a link to the Creative Commons license, and indicate if changes were made.

\section{References}

Brayford, D. (1990). Variation in Phomopsis isolates from Ulmus species in the British Isles and Italy. Mycological Research, 94(5), 691-697.

Chen, L. S., Chu, C., Liu, C. D., Chen, R. S., \& Tsay, J. G. (2006). PCR-based detection and differentiation of anthracnose pathogens, Colletotrichum gloeosporioides and C. truncatum, from vegetable soybean in Taiwan. Journal of Phytopathology, 154(11-12), 654-662.

Diaporthe vaccinii (2009). Bulletin OEPP/EPPO Bulletin, 39, 18-24.

Diogo, E. L. F., Santos, J. M., \& Phillips, A. J. L. (2010). Phylogeny, morphology and pathogenicity of Diaporthe and Phomopsis species on almond in Portugal. Fungal Diversity, 44(1), 107-115.

Elfar, K., Torres, R., Díaz, G. A., \& Latorre, B. A. (2013). Characterization of Diaporthe australafricana and Diaporthe spp. associated with stem canker of blueberry in Chile. Plant Disease, 97(8), 1042-1050.

EPPO (European and Mediterranean Plant Protection Organization) PQR (Plant Quarantine Data Retrieval System) (2014). EPPO database on quarantine pests. Available online from: http://www.eppo.int/DATABASES/pqr/pqr.htm Accessed 28 September 2015.

Espinoza, J. G., Briceño, E. X., Keith, L. M., \& Latorre, B. A. (2008). Canker and twig dieback of blueberry (Vaccinium spp.) caused by Pestalotiopsis spp. and Truncatella sp. in Chile. Plant Disease, 92, 1407-1414.

European Food Safety Authority. (2014). EFSA panel of plant health, scientific opinion on the pest categorisation od Diaporthe vaccinii Shear. EFSA Journal, 12, 3774. 28p.

Fan, J. Y., Guo, L. Y., Xu, J. P., Luo, Y., \& Michailides, T. J. (2010). Genetic diversity of populations of Monilinia fructicola (Fungi, Ascomycota, Helotiales) from China. Journal of Eukaryotic Microbiology, 57, 206-212.

Farr, D. F., Castlebury, L. A., \& Rossman, A. Y. (2002a). Morphological and molecular characterization of Phomopsis vaccinii and additional isolates of Phomopsis from blueberry and cranberry in the Eastern United States. Mycologia, 94(3), 494-504.
Farr, D. F., Castlebury, L. A., Rossman, A. Y., \& Putman, M. L. (2002b). A new species of Phomopsis causing twig dieback of $V$. vitis-idaea (lingonberry). Mycological Research, 106(6), 745-752.

Farr, D. F., \& Rossman, A. Y. (2012). Fungal databases, systematic mycology and microbiology laboratory, ARS, USDA. Retrieved December, 2012, from http://nt.ars-grin. gov/fungaldatabases/.

Friend, R. J., \& Boone, D. M. (1968). Diaporthe vaccinii associated with dieback of cranberry in Wisconsin. Plant Disease Report, 52, 341-344.

Gomes, R. R., Glienke, C., Videira, S. I. R., Lombard, L., Groenewald, J. Z., \& Crous, P. W. (2013). Diaporthe: a genus of endophytic, saprobic and plant pathogenic fungi. Persoonia, 31, 1-41.

Kačergius, A., \& Jovaišiene, Z. (2010). Molecular characterization of quarantine fungus Diaporthe/Phomopsis vaccinii and related isolates of Phomopsis from Vaccinium plants in Lithuania. Botanica Lithuanica, 16(4), 177-182.

Kanematsu, S., Kobayashi, T., Kudo, A., \& Ohtsu, Y. (1999). Conidial morphology, pathogenicity and culture characteristics of Phomopsis isolates from peach, Japanese pear and apple in Japan. Japanese Journal of Phytopathology, 65(3), 264-273.

Lombard, L., van Leeuwen, G. C. M., Guarnaccia, V., Polizzi, G., van Rijswick, P. C. J., Rosendahl, K. C. H. M., Gabler, J., \& Crous, P. (2014). Diaporthe species associated with Vaccinium, with specific reference to Europe. Phytopathologia Mediterranea, 53(2), 287-299.

Ma, Z., Yoshimura, M. A., \& Michailides, T. J. (2003). Identification and characterization of benzimidazole resistance in Monilinia fructicola from stone fruit orchards in California. Applied and Environmental Microbiology, 69, 7145-7152.

MacKenzie, S. J., Peres, N. A., Barquero, M. P., Arauz, L. F., \& Timmer, L. W. (2009). Host range and genetic relatedness of Colletotrichum acutatum isolates from fruit crops and leatherleaf fern in Florida. Phytopathology, 99(5), 620-631.

Milholland, R. D., \& Daykin, M. E. (1983). Blueberry fruit rot caused by Phomopsis vaccinii. Plant Disease, 67, 325-326.

Nilsson, R. H., Kristiansson, E., Ryberg, M., Hallenberg, N., \& Larsson, K. H. (2008). Intraspecific ITS variability in the kingdom fungi as expressed in the international sequence databases and its implications for molecular species identification. Evolutionary Bioinformatics, 4, 193-201.

Olatinwo, R. O., Hanson, E. J., \& Schilder, A. M. C. (2003). A first assessment of the cranberry fruit rot complex in Michigan. Plant Disease, 87(5), 550-556.

Parker, P. E., \& Ramsdell, D. C. (1977). Epidemiology and chemical control of phomopsis canker of highbush blueberry. Phytopathology, 67, 1481-1484.

Polashock, J. J., \& Kramer, M. (2006). Resistance of blueberry cultivars to Botryosphaeria stem blight and Phomopsis twig blight. HortScience, 41, 1457-1461.

Prodorutti, D., Pertot, I., Giongo, L., \& Gessler, C. (2007). Highbush blueberry: cultivation, protection, breeding and biotechnology. The European Journal of Plant Science and Biotechnology, 1, 44-56.

Rehner, S. A., \& Uecker, F. A. (1994). Nuclear ribosomal internal transcribed spacer phylogeny and host diversity in the coelomycete Phomopsis. Canadian Journal of Botany, 72(11), 1666-1674. 
Santos, J. M., Correia, V. G., \& Phillips, A. J. L. (2010). Primers for mating-type diagnosis in Diaporthe and Phomopsis: their use in teleomorph induction in vitro and biological species definition. Fungal Biology, 114(2-3), 255-270.

Santos, J. M., \& Philips, A. L. J. (2009). Resolving the complex of Diaporthe (Phomopsis) species occurring on Foeniculum vulgare in Portugal. Fungal Diversity, 34, 111-125.

Shear, C. L., Stevens, N. E., \& Bain, H. F. (1931). Fungus diseases of the cultivated cranberry. Technical Bulletin, United States Department of Agriculture No 258, 7-8.

Stromeng, G. M., \& Stensvand, A. (2011). Seasonal pattern in production of conidia of Godronia cassandrae f. sp. vaccinii in high bush blueberry in Norway. European Journal of Horticultural Science, 76(1), 6-11.

Tadych, M., Bergen, M. S., Johnson-Cicalese, J., Polashock, J. J., Vorsa, N., \& White, J. F., Jr. (2012). Endophytic and pathogenic fungi of developing cranberry ovaries from flowers to mature fruit: diversity and succession. Fungal Diversity, 54(1), 101-116.

Talhinhas, P., Sreenivasaprasad, S., Neves-Martins, J., \& Oliveira, H. (2005). Molecular and phenotypic analyses reveal association of diverse Colletotrichum acutatum groups and a low level of C. gloeosporioides with olive anthracnose. Applied and Environmental Microbiology, 71(6), 2987-2998.

Tamura, K., Stecher, G., Peterson, D., Filipski, A., \& Kumar, S. (2013). MEGA6: molecular evolutionary genetics analysis version 6.0. Molecular Biology and Evolution, 30(12), 2725-2729.

Udayanga, D., Liu, X. Z., Crous, P. W., McKenzie, E. H. C., Chukeatirote, E., \& Hyde, K. D. (2012). A multi-locus phylogenetic evaluation of Diaporthe (Phomopsis). Fungal Diversity, 56, 157-171.
Udayanga, D., Castlebury, L. A., Rossman, A. Y., Chukeatirote, E., \& Hyde, K. D. (2014). Insights into the genus Diaporthe: phylogenetic species delimitation in the $D$. eres species complex. Fungal Diversity, 67(1), 203-229.

Ureña-Padilla, A. R., Mackenzie, S. J., Bowen, B. W., \& Legard, D. E. (2002). Etiology and population genetics of Colletotrichum spp. causing crown and fruit rot of strawberry. Phytopathology, 92(11), 1245-1252.

Weingartner, D. P., \& Klos, E. J. (1975). Etiology and symptomatology of canker and dieback diseases on highbush bluberries caused by Godronia (Fusicoccum) cassandrae and Diaporthe (Phomopsis) vaccinii. Phytopathology, 65, 105-110.

Weising, K., Weigand, F., Driesel, A. J., Kahl, G., Zischer, H., \& Epplen, J. T. (1989). Polymorphic simple GATA/GACA repeats in plant genomes. Nucleic Acids Research, 17(23), 10128.

White, T. J., Bruns, T., Lee, S., \& Taylor, J. (1990). Amplification and direct sequencing of fungal ribosomal RNA sequencing of fungal ribosomal RNA genes for phylogenetics. In M. A. Innis, D. H. Gelfand, J. J. Sninsky, \& T. J. White (Eds.), PCR protocols: a guide to methods and applications (pp. 315322). San Diego: Academic.

Wilcox, M. S. (1939). Phomopsis twig blight of blueberry. Phytopathology, 29, 136-142.

Wright, A. F., \& Harmon, P. F. (2010). Identification of species in the Botryosphaeriaceae family causing stem blight on southern highbush blueberry in Florida. Plant Disease, 94(8), 966-971.

Zhou, S., Smith, D. R., \& Stanosz, G. R. (2001). Differentiation of Botryosphaeria species and related anamorphic fungi using Inter Simple or Short Sequence Repeat (ISSR) fingerprinting. Mycological Research, 105(8), 919-926. 